\title{
Economic Perspectives on Creativity
}

Lionel Artige, University of Liège, Belgium (lionel.artige@uliege.be)

Todd Lubart, University of Paris (Paris Descartes), France (todd.lubart@parisdescartes.fr)

Forthcoming in Encyclopedia of Creativity (2020), $3^{\text {rd }}$ Edition, Academic Press

\begin{abstract}
$\underline{\text { Abstract }}$
Creativity refers to capacity of human beings to generate new productions or services that have value at the individual or collective level. The economic and social development of humanity since the Neolithic Revolution testifies to the tremendous power of creativity to promote change. This article focuses on explanations and measures of the economic and social consequences of creativity. Main economic theories concerning innovation are described and examined.
\end{abstract}

\section{$\underline{\text { Paper }}$}

In 1994, paintings more than 30,000 years old were discovered in a cave in south-eastern France. Although it may be an early example of art or visual communication, humans did not live very differently at that time from other non-human animals. They lived off what nature had to offer even if evolution endowed the human species with creative potential. However, this way of life, regulated by the rhythm of nature, changed dramatically over the millennia; the invention of agriculture and livestock in the Neolithic era signals the first major economic consequences of creativity, defined as the ability to make productions that are novel and relevant. Human beings became not only consumers of natural resources but also producers, creating, depending on the abundance of crops and livestock, a tradeable potential surplus. This cognitive prowess may seem insignificant to us today because it consisted largely of recreating what nature knew how to create (although cross-breeding animals and plants was a creative act as well as tool making). The accumulation of knowledge necessary for the production of new resources required observation, imagination and testing of different possibilities that only a creative mind could accomplish; these inventions had such economic and social consequences that historians speak of a Neolithic Revolution. From nomadic hunter-gatherers, in a few millennia, people became sedentary farmers on all five continents. ${ }^{1}$ However, this agrarian way of life gave way later to an urban and industrial period characterizing a second economic and social paradigm shift: the Industrial

\footnotetext{
${ }^{1}$ See, for instance, Barker, G. (2009). The agricultural revolution in prehistory: why did foragers become farmers? Oxford University Press.; and Weisdorf, J. L. (2005). From foraging to farming: explaining the Neolithic Revolution. Journal of Economic Surveys, 19(4), 561-586.
} 
Revolution. ${ }^{2}$ It is no longer a question of reproducing what nature produces, but of producing material or immaterial goods that only the human imagination was able to conceive from the accumulation of techno-scientific knowledge. Since then, human life has been subject to an accelerated pace of change, both intentional and unintentional, resulting from people's creative desires, which can be more or less freely expressed according to the culture or laws of the communities to which they belong.

This brief historical overview highlights the growing importance of creativity in the human way of life. In 2010, creativity was cited as one the most important characteristic according to more than 1400 CEOs and global business leaders. But this creative capacity is also solicited among employees, who are increasingly being asked to contribute to the collective creativity of their companies. The objective of this article is to examine the role of creativity in our modern economies and its power as an agent of change.

\section{An economy without creativity}

Imagine a fictitious country populated by individuals with creative abilities but whose culture or law prohibits them from using them. Throughout their lives, individuals are required to respect the order of things in force. At school, teachers teach students the accepted knowledge and punish those who dare to question it or try to discover new ideas. As adults, individuals spend part of their available time producing the set list of goods and services according to imposed technologies inherited from the past. Because private ownership of the means of production is allowed and prices are free, the supply and demand for goods and services adjust to market prices and vary according to consumer preferences. The list of goods and services on the market is therefore fixed, but the quantities produced vary according to consumer demand.

Such a market economy, where creativity is prohibited, is synthesized within Robert Solow's macroeconomic model, which proposed a mechanism for the growth of economic activity based on a given technology inherited from the past and two factors of production, labor and capital (Solow 1956). Workers can thus use tools and machines (capital) manufactured by these same workers according to manufacturing plans inherited from the past to produce the goods and services listed on the known list. In a formal way, the supply of goods and services sold on the markets is represented by the following aggregate production function:

$$
Y_{t}=A f\left(K_{t}, L_{t}\right)
$$

where $Y_{t}$, the output (i.e., the Gross Domestic Product of the fictitious country), is the quantity of goods and services produced and sold at market prices in the country in year $t$, $K_{t}$ and $L_{t}$ are, respectively, the quantities of physical capital stock and labor used for the

${ }^{2}$ See, for example, a historical account of the Industrial Revolution: Landes, D. S. (1969). The unbound Prometheus: technological change and industrial development in Western Europe from 1750 to the present. New York: Cambridge University Press. 
production of output in year $t, f$ is the transformation function of inputs ( $K$ and $L$ ) into output $(Y)$ and $A$ represents the level of productivity with which the country is able to transform these inputs into the output.

Is economic change possible in our fictitious country? If so, can this change translate into economic growth (i.e., an increase in per capita income over time)? Economic change is possible in such a country but it is limited. Some characteristics are invariant. As indicated in equation (1), the level of productivity $A$ and the production processes represented by $f$ are constant in this economy. Output $Y$, capital $K$ and labor $L$ are homogeneous goods, i.e., that their characteristics cannot change. In contrast, the quantities of $Y, K$ and $L$ can vary upwards as well as downwards. For example, labor $L$ varies according to population growth. The capital $K$ varies according to the number of machines manufactured and the number of machines that have become unusable. Output $Y$ depends on the quantities $K$ and $L$ used in the production processes. Economic change is therefore possible but limited to a single source: the variation in the ratio of quantities of factors of production used in production, known as the capital-labor ratio $(K / L)$.

Is this limited economic change sufficient to generate economic growth? Assuming that marginal returns to capital and labor decrease as their quantities increase, Solow (1956) showed that such an economy could grow in the short term but not in the long term. In the short term, the accumulation of capital stock per worker, i.e. the change in the capital-labor ratio $(K / L)$, allows an initially underdeveloped economy to grow temporarily. Growth ends when the return on capital does not allow investment beyond what is necessary to replace capital that has become unusable over time. In other words, our fictitious country can experience temporary development by providing tools and machines to workers and thus produce more of the same official list of goods and services. This capital therefore allows workers to be more productive. Each time workers receive an additional quantity of tools and machines, they produce more but with an increasingly lower return. Workers' productivity therefore reaches a maximum over time when the production resulting from an additional quantity of capital just covers the cost of that capital. Beyond this maximum, the cost is higher than the gain, which reduces workers' productivity. There is therefore a level of the capital-labor ratio above which growth in income per worker is no longer possible. A decline in population growth or a change in individual preferences may temporarily raise the per capita income growth rate above zero, but in the long run, this growth rate will always eventually return to zero.

In summary, a country, where creativity is prohibited, may experience limited economic change and temporary economic growth but not the long-term growth that has characterized Western countries' growth since the Industrial Revolution.

\section{Innovation: the engine of modern economic growth}

Solow (1957) sought to estimate the share of US economic growth between 1909 and 1949 that could be explained by the change in the labor-capital ratio. Despite the difficulty of measuring capital, his calculations showed that whereas US per capita income had doubled 
over this period of 40 years, only about $12 \%$ of this growth was attributable to capital and labor growth. This result has been repeatedly confirmed by other studies thereafter, for the United States but also for other countries. As for the remaining $88 \%$ of growth, economists have called it the "Solow residual", i.e., according to Abramovitz's (1956) famous formula, "a measure of our ignorance"!

Solow's work has shown that the accumulation of factors of production (capital and labor) is a necessary but not sufficient condition to explain the continued economic growth that Western countries have experienced since the Industrial Revolution. ${ }^{3}$ Economists have therefore sought to explain Solow's residual. ${ }^{4}$ The roadmap was ultimately clear. It was sufficient to release all the assumptions of invariance in Solow's model:

$1 /$ Productivity is not fixed but progresses over time through the critical evaluation of acquired technological knowledge and the production of new knowledge to improve productivity. This change in technological knowledge raises its level, represented by variable $A$, which becomes $A_{t}$ in equation (1) because it now varies over time.

2/ Production processes are not invariant but change with technological progress and the experience (learning by doing) acquired by producers. The efficiency of these production processes improves over time if they are more economical in terms of production factors. The function $f$, representing these production processes, therefore becomes $f_{t}$ in equation (1) because it can change over time.

3 / The labor force $L$ is not a homogeneous force fixed in time. Workers' productivity changes with knowledge acquired at school and in the workplace. In other words, the labor force can also change qualitatively as a result of the progress of knowledge. The labor force thus becomes a kind of capital, human capital, in which we can invest.

Part of this human capital consists of a set of cognitive, emotional and conative resources relevant to creativity. The level of these resources can develop throughout an individual's life and varies mainly between individuals. A large body of research in psychology has investigated the precise nature of the set of resources that support creativity. Two points deserve to be highlighted. The first concerns the likely non-linearity between these resources necessary for creativity (Rubenson and Runco 1992, Sternberg \& Lubart, 1995). Whereas a minimum level of resources is required to show creativity, excessive amounts of certain resources (such as evaluative ability) may be show diminishing contributions to creative performance. The second is a potential inverted U-shaped relationship between knowledge and formal education (Simonton 1997). School allows individuals to acquire existing knowledge, thus enabling new generations to avoid reinventing the wheel and making known mistakes. However, as the individual acquires

\footnotetext{
${ }^{3}$ According to historical statistics by Maddison (2001), per capita income in Western European and North American countries grew at an average annual rate of between 1.5 and 2\% over the period 1820-2000.

${ }^{4}$ These economists belong to the research field of endogenous growth theory. The main contributions of this theory are due to Romer, Lucas, and Aghion and Howitt. See Aghion and Howitt (2008) for an overview of this literature.
} 
existing knowledge, flexibility of thought may be reduced, and calling the acquired knowledge into question may be seen as devaluing one's hard-earned cognitive assets.

4/ Physical capital $K$ is no more homogeneous than labor. Workers are able to improve existing machines and invent new ones. The capital can therefore also change qualitatively.

5/ Output $Y$ is not an official list of goods and services. Producers are able to change the quality of existing goods or manufacture new ones. The list of varieties of the supply is therefore variable.

Equation (1) then becomes

$$
Y_{t}=A_{t} f_{t}\left(\alpha_{t} K_{t}, \gamma_{t} L_{t}\right)
$$

where year $t$ symbolizes the variation of all components of production over time, $\alpha_{t}$ is the efficiency of capital quality $K_{t}$ and $\gamma_{t}$ is the efficiency of labor quality $L_{t}$. Production is now no longer a fixed but a variable list of goods and services

$$
Y_{t}=\sum_{i}^{N_{t}} p_{i, t} y_{i, t}
$$

where $y_{i, t}$ are the quantities produced of these goods and services whose $N_{t}$ list varies over time. These goods and services are sold at market prices $p_{i, t}$.

All the changes mentioned above are qualitative changes that can be made to the production of goods and services. These qualitative changes are what economists call innovations made by individuals with creative abilities. In economics, innovation can be defined as "the application of new ideas to the products, processes, or other aspects of the activities of a firm that lead to increased value" (Greenhalgh and Rogers, 2010, p. 4).

Formerly, the value created by innovation at the firm level is equal to

$$
V=q-c
$$

where $V, q$ and $c$ are, respectively, the nominal monetary net value, the nominal sales revenues and the nominal cost of the innovation. The cost of innovation refers to the production costs of the innovation and, in addition, the expenditures on research and development which made it possible to design the innovation before it was produced. This cost thus includes expenditure on capital, labor and intermediate consumption necessary for the design and production of the innovation. The value created by innovation is included in the firm's total profits. If $V \geq 0$, then the innovation is a success. Otherwise, it is a failure.

At the source of any innovative process, there is a new idea and the new idea is the output of a creative process. Psychological research on creativity provides insight into this creative process. Creative ideas seem to come from a combination/association of remote concepts. 
The association of remote concepts does not proceed in a random way but is guided by a selection process that depends on the knowledge of individuals as well as their emotions. Lubart and Getz have argued that emotional information is a key resource in the preconscious processing of concept combinations and certain emotional abilities are essential for the recognition of these combinations. In firms, the creative process is more and more collective. It is therefore essential for them to activate the cognitive and emotional resources of employees to foster the development of creative ideas at the individual and collective level.

An innovation is therefore a creative idea that has found a market opportunity. If culture or law allows individuals in our fictitious country to use their creative abilities, then human creativity can exert a powerful force for change in the economy.

Can the economic change resulting from human creativity fill the remaining Solow residual and thus explain long-term economic growth? Equation (4) shows clearly that if $\mathrm{V} \geq 0$ then innovation brings a benefit to the firm. Economic change is therefore positive at the microeconomic level, i.e. at the level of the innovative firm. But is it necessarily positive at the macroeconomic level? In a creative economy, new goods and services enter the market alongside and in place of existing goods and services. In other words, innovations create new activities and jobs but also destroy existing activities and jobs. This phenomenon, described by Schumpeter (1942) as 'creative destruction', can take place within the innovative firm itself, when it sells several competing products, and between firms. Among the beneficiaries of innovation are the innovative firm itself and other firms that would use this innovation in their production process. This innovation is then either a new good or service entering the manufacturing process (intermediate consumption), a new capital good (factor of production) or a new manufacturing method (production process). In any case, innovation, through an externality effect, offers a value gain to those firms that use this innovation without having created it. Among the victims of innovation are firms that suffer a loss of value as a result of the competitor's successful innovation. But if this innovation does not allow the innovative firm to cover its research and development costs, then the innovation causes it to suffer a loss. Innovation therefore has a positive macroeconomic effect if the value created in the economy outweighs the value destroyed.

Is this always the case? In a competitive economy, the answer is yes. Every day, firms compete to sell their goods and services to buyers who are consumers in the business-toconsumer market and firms in the business-to-business market. Because buyers' budgets are limited, firms must do everything possible to ensure that the quality and price of their goods and services convince buyers. While competition regulators ensure that free market entry is respected, competition operates not only between existing firms but also with new firms entering the market. This competition is the market incentive that drives firms to use human creativity to improve their supply of goods and services through more attractive quality at the best price. Competition thus promotes the emergence of creative ideas and the market, i.e. the demand expressed by buyers, selects the most efficient. The innovations sold on the market are necessarily the creative ideas that have overcome all the challenges of the competition. To remain or be more efficient, firms must research and succeed in their 
innovations. Thus, in competitive markets, firms that succeed in maintaining or increasing their efficiency push out those whose efficiency is declining. For this reason, the macroeconomic effect of innovation is necessarily positive (see Figure 1 for a model of growth processes resulting from creativity).

How can this net macroeconomic value creation be measured? A first approach consists of using company accounts as a starting point. But because innovation creates and destroys value, it is difficult to identify the costs and benefits of innovation in firms' accounts and thus to obtain, by aggregating these costs and benefits, an indicator of the macroeconomic effect of innovation. The other approach is based on the measurement of economic growth, i.e. the variation over time of firms' added values. However, as already mentioned, economic growth is the result of economic change resulting from a quantitative change in production factors and qualitative economic change resulting from innovation. However, we have seen that the decomposition of growth proposed by Solow (1957) made it possible to roughly distinguish the two. The Solow residual can therefore be considered as a measure of the macroeconomic effect of innovation. Given the size of this residual in most empirical studies, it can be concluded without reservation that innovation is the driving force behind long-term economic growth.

However, although positive, the creation of net macroeconomic value has an economic and social cost as new firms emerge and create jobs whereas others disappear with their jobs. In addition, the jobs created often require different qualifications from those of the jobs destroyed, forcing workers to undergo lifelong training to adapt to the requirements of new jobs. This reallocation of jobs from declining to innovative firms benefits mainly new generations and the most skilled workers. Economic change induced by human creativity thus creates both macroeconomic value and social discrimination.

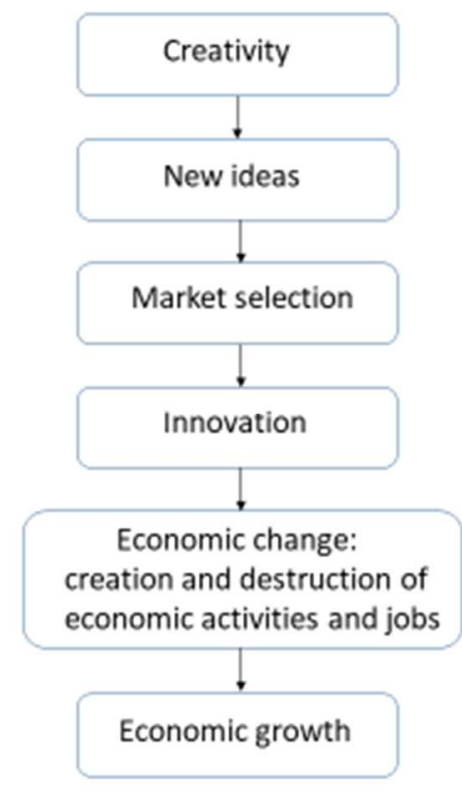

Figure 1. A Simplified Growth Model of Creativity 
Economists assume that a firm's objective is to maximize its profit. In a competitive market, profit maximization aims to avoid the risk of the firm's bankruptcy. Audretsch (1991) estimated on US data that only one in two firms was still in business after 6 years and one in three after 10 years. The same author observed that US firms that innovated increased their probability of survival. As already explained, innovative firms that manage to gain a foothold in competitive markets have de facto convinced buyers with new, better or cheaper products. As the buyers' budget is limited, there is not room for everyone. This is why innovative firms drive firms that are less innovative or not sufficiently innovative into bankruptcy. Competition is therefore a powerful incentive to seek innovation. For this, firms have two possibilities. Either they organize within themselves a research and development department to generate creative ideas that they use for their benefit or that they sell on the market, which can be called the creative ideas market. Either they buy creative ideas from individuals, universities or other firms in the same creative ideas market. Some firms use both possibilities. But this has a cost that is not always rewarded. There are many innovations that fail, which also explains the high mortality rate of firms. They must therefore decide between the risk of going bankrupt because they do not innovate and the risk of going bankrupt because their innovations fail. Moreover, even if their innovations are successful, firms face an additional risk: the theft of creative ideas in various forms such as industrial espionage, imitation or counterfeiting. This risk is an existential threat not only to innovative firms but also to the economy as a whole because firms cannot protect themselves against this risk on their own. The creative idea is a "good" that is easy to steal because of its particular characteristics. It is an inappropriable good, i.e. the good is non-rival (several people can consume the same good at the same time) and non-excludable (it is difficult or even impossible to prevent others from consuming the good by varying its price). There is therefore a strong temptation for firms to appropriate the creative ideas of other firms as soon as they are communicated and to sell the resulting innovations to buyers who can benefit from them at immediately competitive prices. Everyone benefits from creative ideas except, sometimes, the firms that produce them. That is where the problem lies. These creative firms invest money in research and development to generate new ideas. If the market price of the innovations resulting from these ideas is not high enough, then the profit of these firms will not cover the initial investment. If competitors can appropriate creative ideas without having to buy them, why should firms make the effort to spend on research and development to produce them? Arrow (1962) showed that production in a market where the good is inappropriable by its producer was socially non-optimal. This market failure is serious. On the one hand, it is desirable that access to creative ideas be as broad as possible. Indeed, the creative idea is not the result of an ex nihilo process. It is always built on knowledge, experience, existing ideas and informational exchanges between individuals. In turn, the creative idea enriches the stock of existing knowledge that will inspire other creative ideas. This stock of knowledge accumulated over time must therefore be a collective ground from which individuals or teams from firms can draw their inspiration. On 
the other hand, it is desirable that the production of creative ideas be rewarded in one way or another, without which the stock of knowledge cannot progress. The market alone cannot guarantee both the production of creative ideas to increase the stock of knowledge and the widest possible access to it. The probably imperfect solution that market economies have provided to this market failure is legal rules and regulations: the creation of an intellectual property right for authors of creative ideas and temporary legal protection of innovations (patents and copyrights). Thanks to this legal protection, innovative firms make their new ideas available to the public in exchange for a time-limited payment for the use of these ideas by other firms. Firms can therefore apply for legal protection of their inventions to a patent office, which must decide on their creativity in order to grant it. The first law on the protection of inventions (Parte Veneziana) was promulgated by the Republic of Venice in 1474. This law is the historical testimony of the importance of the economic value taken from that time on by creativity and the difficulty of inventors to appropriate this value. Since that time, as evidenced by statistics from the World Intellectual Property Organization (WIPO), the demand for legal protection of inventions has increased steadily, confirming more than ever the economic value of creativity and the vital need for firms to innovate.

\section{Creativity: the unlimited frontier of economic development in a finite environment?}

Throughout history, humans have been able to exploit their potential to create resources, material and immaterial goods. This production has enabled the demography of the human species to grow rapidly and has profoundly changed our way of life (Livi-Bacci 2017). Humanity's tremendous economic development is largely the result of human creativity. If this creativity can be encouraged, then economic development will be enhanced. However, creativity, and resulting productivity and economic growth also impact the balance within human societies and between humans and the planet. It will require additional human creativity to solve challenges facing the world, be they environmental or social, which themselves have resulted from activity at the interface between creativity and economics.

\section{References}

Aghion, P., \& Howitt, P. W. (2008). The economics of growth. Cambridge, MA: MIT press.

Arrow, K. (1962), Economic welfare and the allocation of resources for invention, in The rate and direction of inventive activity: economic and social factors, NBER, 609-626.

Abramovitz, M. (1956). Resource and output trends in the United States since 1870. NBER, 1-23.

Audretsch, D. B. (1991). New-firm survival and the technological regime. Review of Economics and Statistics, 441-450. 
Greenhalgh, C., \& Rogers, M. (2010). Innovation, intellectual property, and economic growth. Princeton, NJ: Princeton University Press.

Grossman, G. M., \& Helpman, E. (1993). Innovation and growth in the global economy. Cambridge, MA: MIT press.

Livi-Bacci, M. (2017). A concise history of world population. John Wiley \& Sons.

Maddison, Angus (2001). The world economy: a millennial perspective. Paris: OECD.

Rubenson, D.L. and Runco, M. A. (1992). The psychoeconomic approach to creativity. New Ideas in Psychology, 10(2), 131-147.

Schumpeter, J. A. (1942). Capitalism, Socialism and Democracy.

Simonton, D. K. (1997). Creative productivity: A predictive and explanatory model of career trajectories and landmarks. Psychological Review, 104, 66-89.

Solow, R. M. (1956). A contribution to the theory of economic growth. Quarterly Journal of Economics, 70(1), 65-94.

Solow, R. M. (1957). Technical change and the aggregate production function. Review of Economics and Statistics, 39(3), 312-320.

Sternberg, R.J., \& Lubart, T. (1995). Defying the crowd. New York: Free Press.

Additional readings

Lubart, T. \& Getz, I. (2011). Economic perspectives on creativity. In M. A. Runco \& S. R. Pritzker (Eds.) Encyclopedia of creativity, 2nd edition (pp. 429-434). New York: Academic Press.

Lucas Jr, R. E. (1988). On the mechanics of economic development. Journal of Monetary Economics, 22(1), 3-42.

Romer, P. M. (1990). Endogenous technological change. Journal of Political Economy, 98(5, Part 2), S71-S102. 